\title{
Data Standard
}

National Cancer Institute

\section{Source}

National Cancer Institute. Data Standard. NCI Thesaurus. Code C103180.

A statement that defines conventions, guidelines, characteristics or methods for consistent data handling to facilitate exchange or processing of the data. This set of criteria are reviewed by and agreed upon by the user community or a governing body before they are released and adopted for use. 